\title{
Goldfish as a model for studying the effect of hypernatremia on blood plasma lipoproteins
}

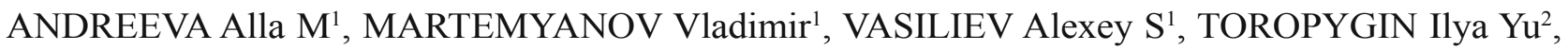 \\ LAMASH Nina ${ }^{1,3}$, GARINA Darina $V^{1}$, PAVLOV Dmitry ${ }^{1}$
}

Papanin Institute for Biology of Inland Waters, Russian Academy of Sciences, Nekouzskii raion, Borok, Yaroslavl oblast, Russia. aam@ibiw.ru

\begin{abstract}
AIM: To evaluate the effect of hypernatremia on the organization of blood plasma high density lipoproteins (HDL) in goldfish; to compare the state of hypernatremia in fish and humans; to assess the possible risks and consequences of the effect of hypernatremia on human plasma lipoproteins.

METHODS: The fish were acclimated for 20 days at a critical salinity of $11.5 \mathrm{~g} / \mathrm{L}$; after that the salt water was gradually "desalinated". The concentration of $\mathrm{Na}^{+}$and the content of total water were determined in tissues, cells, and body fluids. The HDL organization was assessed by the number of apolipoprotein molecules per particle. The methods of flame spectrophotometry, electrophoresis and MALDI were used.

RESULTS: In fresh water, the state of normonatremia was maintained in the fish body; at critical water salinity, the state of hypernatremia. Against the background of hypernatremia, the initial signs of muscle and erythrocyte dehydration appeared in fish, the total water content in the plasma did not change, and HDL disintegrated into small particles, which, upon restoration of normonatremia, were combined into the original large forms.

CONCLUSION: In goldfish at the state of normonatremia, large forms of HDL are stable while at the state of hypernatremia, the small forms of HDL are stable. Under conditions of a hypertonic environment and plasma hypernatremia, the breakdown of HDL prevents the loss of water from the fish organism and reduces the threat of their dehydration. Human hypernatremia is characterized by plasma sodium levels comparable to that in goldfish, however accompanied by life-threatening metabolic changes. The results of this study may be useful for assessing the risks of HDL breakdown at hypernatremia and for the development of protocols for the treatment of pathological conditions in humans (Fig. 4, Ref. 45). Text in PDF www.elis.sk KEY WORDS: goldfish, blood plasma high density lipoproteins, hypernatremia.
\end{abstract}

\section{Introduction}

The sodium concentration in human plasma is normally maintained in the range $130-145 \mathrm{mmol} / \mathrm{kg}(1,2,3,4,5)$. In case of violations of ionic homeostasis, which are often found in clinical practice, the sodium content in the plasma changes beyond the normal range and manifests itself in the form of dysnatremia (6), often ending in death (7). With hyponatremia, the concentration of sodium in the plasma drops below $130 \mathrm{mmol} / \mathrm{kg}$, while with hypernatremia it rises above $145 \mathrm{mmol} / \mathrm{kg}$, reaching $200 \mathrm{mmol} /$ $\operatorname{kg}(6,8,9,10,11,12,13)$.

\footnotetext{
${ }^{1}$ Papanin Institute for Biology of Inland Waters, Russian Academy of Sciences, Nekouzskii raion, Borok, Yaroslavl oblast, Russia, ${ }^{2}$ Institute of Biomedical Chemistry, Russian Academy of Sciences, Moscow, Russia, and ${ }^{3}$ Zhirmunsky National Scientific Centre of Marine Biology, Far Eastern Branch, Russian Academy of Sciences, Vladivostok, Russia

Address for correspondence: A. M. ANDREEVA, Papanin Institute for Biology of Inland Waters, Russian Academy of Sciences, Borok 152742, Nekouzskii raion, Yaroslavl oblast, Russia

Acknowledgements: This study was carried out as part of State Task AAAA-A19-119102890013-3 and 121050500046-8).
}

Proteins and, in particular, protein complexes may be the "targets" of increased $\mathrm{Na}^{+}$concentration. Their response to an increase in sodium levels may be manifested in a change in the profile of protein-protein interactions and the balance of dissociation-association processes. High-density lipoproteins (HDL) are also organized by the type of complexes - from proteins and lipids associated with each other. HDL serves as factors of complex defence of the organism (14) and is present in all vertebrates $(15,16)$. Proteins account for about $80 \%$ of the HDL surface, and apolipoproteins dominate; the "minor" fraction is represented by $\sim 100$ proteins, the majority of which are not associated with lipid transport $(14,17)$. Hypernatremia can provoke the breakdown of blood plasma HDL and a change in the activity of proteins in the composition of the particles.

The range of plasma sodium concentration in freshwater teleosts is comparable to that of mammals $(18,19)$. In the conditions of extremely high critical water salinity (CS) tolerated by fish, the sodium concentration in their plasma increases to $\sim 190-206$ $\mathrm{mmol} / \mathrm{kg}(10,18,20)$. This level is comparable to the level of $\mathrm{Na}$ ${ }^{+}$in human plasma at the state of hypernatremia. The coincidence of the ranges of variation of sodium concentration in the plasma of humans and fish, on the one hand, and the presence in their plasma 
of potential "targets" of high sodium concentration in the form of HDL, on the other hand, give grounds for using fish as models for studying the effect of $\mathrm{Na}^{+}$on blood plasma HDL organization.

The goal of the present paper is to analyse the effect of hypernatremia in goldfish Carassius auratus on the organization and pattern of remodelling (reversible/irreversible) of blood plasma HDL.

\section{Materials and methods}

\section{The object and experiment design}

The object of the study were the female goldfish Carassius auratus L. (Cypriniformes; Cyprinidae), caught in September in the Rybinsk Reservoir. For the experiment, 40 females with gonads at the III stage of maturity and body length of $15-22 \mathrm{~cm}$ were selected. The fish were placed in two aquaria (aq) with fresh water (FW), at a density of 10 fish per 100 litres of water. The water temperature was maintained at $10.0-11.0^{\circ} \mathrm{C}$. All the aquaria were artificially aerated. During the experiments, the fish were not fed. A control group kept in fresh water ("FW" group, 20 fish) was placed in a freshwater aquarium (aq1). The remaining fish were placed into the aq2 with $\mathrm{FW}$; and three days later, $\mathrm{NaCl}$ was added at a rate of 1.0 grams per kilogram of water per day. After 12 days in aq2, a critical salinity (CS) level of $11.5 \mathrm{~g} / \mathrm{kg}$ was reached. The fish were kept in these conditions for 20 days ("CS" fish group). After that, biological materials were sampled from 10 specimens, in parallel with the biological materials from the control group (sampling 1). The rest of the fish (aq2) were subjected for 12 days to gradual desalination of water by the replacement of salt water with portions of FW. Upon reaching the complete "desalination" of water, the fish were kept in FW for another 14 days ("FW fish group); then the biomaterials were sampled in parallel with the control group (sampling 2).

\section{Analysed biological samples}

The following samples were analysed: Body fluids - blood plasma, cerebrospinal fluid (CSF); tissues - liver, skeletal muscles, brain; cells - erythrocytes.

\section{Methods}

Blood was collected from the caudal vein. To obtain plasma, individual blood samples were collected in tubes with a $1 \%$ heparinoid solution and centrifuged at room temperature for 15 minutes at $1400 \mathrm{~g}$.

The sampling protocol for the tissues of liver, skeletal muscles, brain, erythrocytes and CSF was described in detail in (21).

The content of total water $(t w)$ in samples was determined according to protocol described in (22).

The concentrations of $\mathrm{Na}^{+}(\mathrm{mmol} / \mathrm{kg})$ in biological samples and in aquarium water were measured using Flapho-4 flame spectrophotometer (Carl Zeiss, Jena, Germany). Then, the difference between these concentrations was calculated $\left(\Delta \mathrm{Na}^{+}\right)$.

The protein concentration in plasma was measured using the microbiuret test (23).

Disk-electrophoresis (disk-E) in PAG, 2D-E in 5-40 \% PAG and $12.5 \%$ SDS-PAG (24), were used to separate blood plasma proteins. The polymeric forms of human serum albumin $(67,134$, $201,268,335 \mathrm{kDa})$, ovalbumin $(45,90,135 \mathrm{kDa})$ and myoglobin $(16,32,64 \mathrm{kDa})$ (Serva, Germany) and PageRulerTM Prestained Protein Ladder Plus (11, 17, 28, 36, 55, 72, 95, 130, 250 kDa) (Fermentas, USA) were used as markers of molecular weight (Mr).

$\mathrm{Mr}$ values for apolipoproteins (ApoA-I, Apo-14) and HDL; ApoA-I/Apo-14 molar ratio; the number of Apo molecules in 1 HDL particle -were calculated using ONE -Dscan, Ver 1.31 (Scananalytic Inc.) software package.

For protein identification, the MALDI mass spectrometry was used. The mass spectra $(\mathrm{ms})$ of trypsin-digested proteins were obtained using a MALDI-TOF/TOF mass-spectrometer (UltrafleXtreme Bruker Daltonics, Germany). To analyse the ms, FlexAnalysis 3.3 software (Bruker Daltonics, Germany) was used. The proteins were identified using the MASCOT search software ("peptide fingerprint" option; www.matrixscience.com). The search was carried out in the NCBI and/or EST vertebrates DB. Candidate proteins were considered to be reliably identified at score $>83(\mathrm{p}<0.05)$.

Results are presented as the means and the standard error of the means ( \pm SEM). A comparative analysis of the obtained data was carried out using the Mann-Whitney test for unpaired statistics, with $\mathrm{p} \leq 0.05$ as the threshold for statistical significance.

\section{Results}

\section{Organization of goldfish blood plasma HDL}

On the plasma protein electropherogram, HDL is either adhered tightly to transferrin (AAK92216.1; transferrin precursor (Carassius gibelio); 73939 Da; score 203) or "covered" (Fig. 1). Two proteins adjoined the HDL from the anode side: serine proteinase inhibitors serpins (P32759.1; Full=Alpha-1-antitrypsin homolog; Flags: Precursor (Cyprinus carpio); 41873 Da; score 82 ) and "warm temperature acclimation related $65 \mathrm{kDa}$ protein" (BAP90357.1; warm temperature acclimation related $65 \mathrm{kDa}$ protein-1 (Carassius carassius); $50773 \mathrm{Da}$; score 145) (Fig. 1).

In the fish of "FW" and " $F W_{\text {rev }}$ " groups, HDL were located on the electrophoregram in the area with Rf $0.45-0.63$; in the

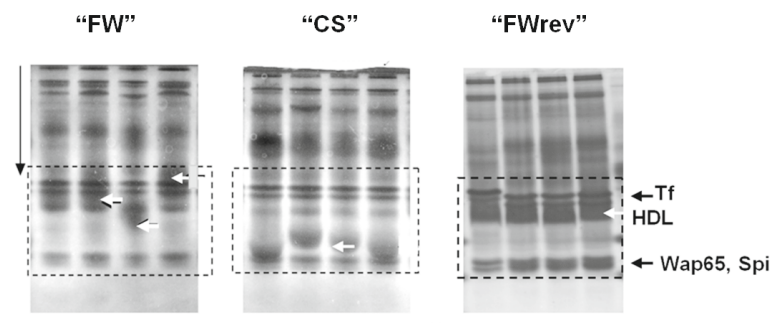

Fig. 1. Disk- E of goldfish plasma proteins from "FW", "CS" and "FW rev" groups. The low molecular protein fractions, including transferrin (Tf), HDL, warm temperature acclimation related $65 \mathrm{kDa}$ protein (Wap65) and serine proteinase inhibitors (Spi) are highlighted with a dotted line. Vertical arrow on the left indicates the direction of movement of proteins. Small horizontal white arrows indicate the position of HDL; the black arrows, the positions of Tf, Wap65 and Spi. 
172-177
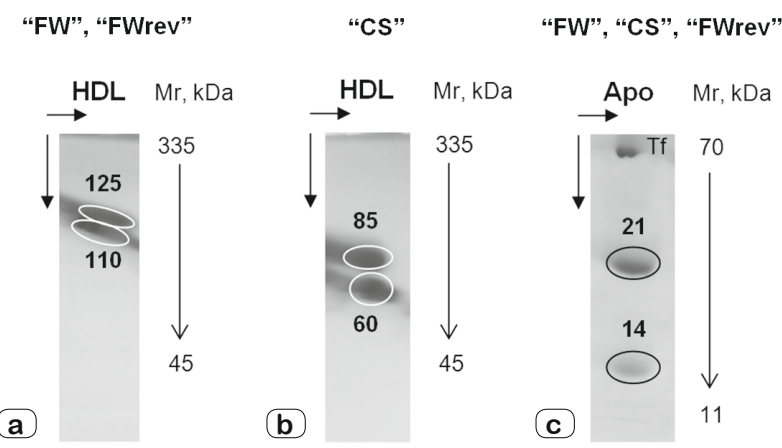

Fig. 2. Fractionating of goldfish plasma HDL in 5-40 \% PAGE (a, b) and Apo in HDL composition in SDS-PAGE (c) from "FW", "CS" and "FW ${ }_{\text {rev }}$ " groups (fragments of electrophoregrams): 125 and $110 \mathrm{kDa}$ HDLs (a); 85 and 60 kDa HDLs (b); 21 kDa ApoA-I and 14 kDa Apo-14 (c). White ovals mark HDL "spots" and dark ovals mark Apo "spots". To the right of electropherograms there are a Mr scales.
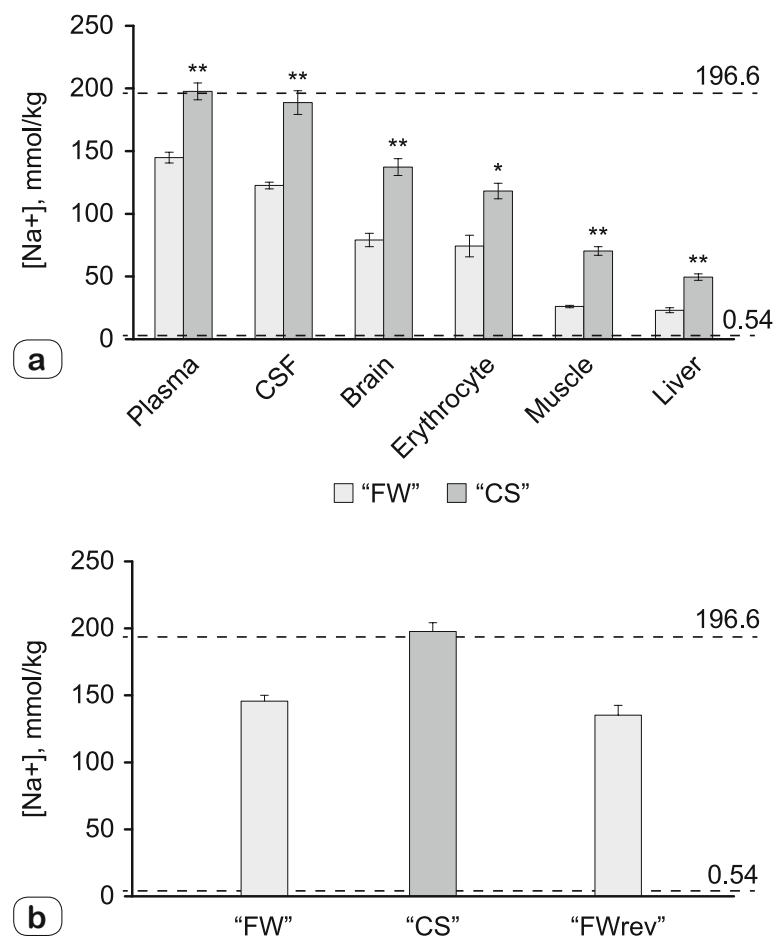

Fig. 3. $\mathrm{Na}^{+}$concentration in biological samples of goldfish in fresh water (no fill) and critical salinity (dark fill) conditions (a), and its changes in blood plasma in the fish of "FW", "CS" and "FW " groups (b). The dashed lines and the values 0.54 and $196.6(\mathrm{mmol} / \mathrm{kg})$ indicate the concentrations of $\mathrm{Na}^{+}$in fresh water and CS, respectively. Differences are statistically significant at $\mathbf{p}<0.05(*)$, at $\mathbf{p}<0.01\left({ }^{* *}\right)$.

"CS" group they shifted toward the anode to the region with $\mathrm{Rf}$ $0.63-0.72$ (Fig. 1).

The values of the total protein concentration in the plasma of

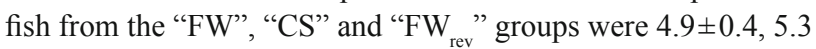
\pm 0.8 and $4.6 \pm 0.4 \mathrm{~g} \%$, respectively. The relative contents of HDL in the plasma of fish from these groups were $27.4 \pm 6.3,29.6 \pm 3.8$ and $26.8 \pm 5.1 \%$ respectively.

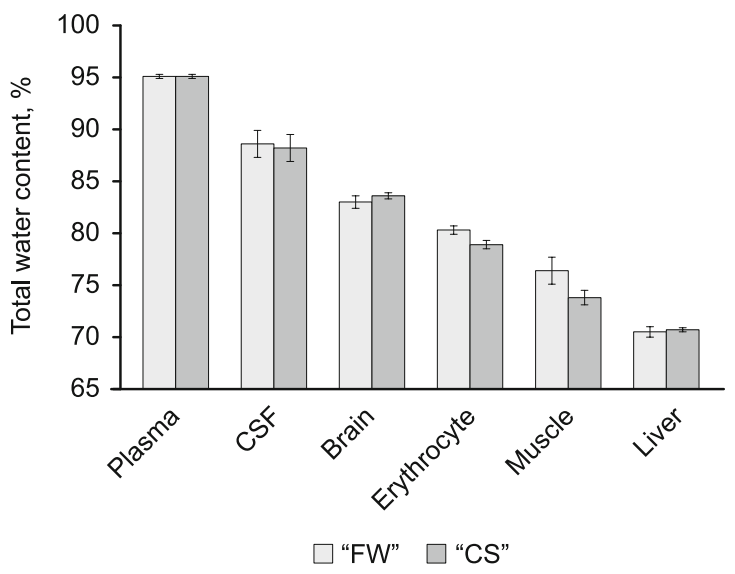

Fig. 4. Content of total water in tissue, cells and fluids samples of goldfish from "FW" (no fill) and "CS" (dark fill) groups.

In the fish of "FW" and " $F W_{\text {rev }}$ " groups, native $\mathrm{HDL}$ were represented by two types of particles with $\mathrm{Mr} \sim 125$ and $\sim 110 \mathrm{kDa}$ (Fig. 2a). In denaturing PAGE, they disintegrated into $\sim 21$ and $\sim 14$ $\mathrm{kDa}$ proteins, identified as the ApoA-I (APOA1_DANRE; Apolipoprotein A-I OS=Danio rerio $\mathrm{GN}=$ apoa1 $\mathrm{PE}=2 \mathrm{SV}=1 ; 30237$ Da; score 257) and Apo-14 (AAW82445.1; $14 \mathrm{kDa}$ apolipoprotein (Carassius gibelio); 15771 Da; score 104) respectively (Fig. 2c).

In the "CS" group, native HDLs were represented by $\sim 85$ and $60 \mathrm{kDa}$ particles (Fig. 2b). Under denaturing conditions, these particles also disintegrated into $\sim 21$ and $14 \mathrm{kDa}$ proteins, identified as apolipoproteins ApoA-I (APOA1_DANRE; Apolipoprotein A-I OS=Danio rerio $\mathrm{GN}=$ apoa1 $\mathrm{PE}=2 \mathrm{SV}=1 ; 30237 \mathrm{Da}$; score 257 ) and "14 kDa apolipoproteins" (Apo-14) (AAW82445.1; 14 $\mathrm{kDa}$ apolipoprotein (Carassius gibelio); $15771 \mathrm{Da}$; score 104), respectively (Fig. 2c).

Analysis of the HDL organization parameters made it possible to distinguish two discrete types of these particles. Thus, in the fish of "FW" and "FW " " groups, the plasma contains only large $\operatorname{HDL}(125,110 \mathrm{kDa})$; in the "CS" group, only small HDLs $(85,60$ $\mathrm{kDa}$ ). In all particles, the molar ratio of apolipoproteins was close to equimolar $(\sim 1: 1)$, except for $85 \mathrm{kDa}$ particles, in which it was $\sim 3: 2$. The number of Apo molecules in HDL particles was different. One $125 \mathrm{kDa}$ particle contains 3-4 molecules of each Apo (6-8 molecules in total); one $110 \mathrm{kDa}$ particle -3 molecules of each Apo (6 in total); one $85 \mathrm{kDa}$ particle - 3 ApoA-I and 2 Apo14 molecules ( 5 in total), and the $60 \mathrm{kDa}$ particle -2 molecules of each Apo (4 in total).

The breakdown of large particles into small forms was reversible, since the original large forms were found again in the blood of fish transferred to FW after 20 days of acclimation to CS.

\section{Parameters of water-salt homeostasis}

The concentration of $\mathrm{Na}^{+}$in the biological samples of the fish in CS conditions was higher than in FW (Fig. 3a). The $\mathrm{Na}^{+}$concentration values in the plasma were $144.8 \pm 4.3 \mathrm{mmol} / \mathrm{kg}$ in " $\mathrm{FW}$ " group fish and $197.6 \pm 6.7 \mathrm{mmol} / \mathrm{kg}$ in " $\mathrm{CS}$ ". In the " $\mathrm{FW}_{\text {rev }}$ "group, the $\mathrm{Na}^{+}$content did not differ from the control values (Fig. 3b). 
The $\mathrm{Na}^{+}$contents in the aquarium water were $0.03 \mathrm{~g} / \mathrm{L}(0.54 \mathrm{mmol} /$ $\mathrm{kg})$ in $\mathrm{FW}$; and $11.5 \mathrm{~g} / \mathrm{L}(196.6 \mathrm{mmol} / \mathrm{kg})$ in CS; consequently, the $\Delta \mathrm{Na}^{+}$values were $\sim 144 \mathrm{mmol} / \mathrm{kg}$ for goldfish in $\mathrm{FW}$ and $\sim 1$ $\mathrm{mmol} / \mathrm{kg}$ for goldfish in CS (Fig. 3b).

Comparison of the "FW" and "CS" groups in parameter of $t w$ content in plasma, CSF, brain, muscles, erythrocytes, and liver did not reveal significant differences (Fig. 4). In the CS conditions, the tw content in muscles and erythrocytes was slightly lower than in the control; in muscles it was $80.3 \pm 0.4 \%$ (FW) and $78.9 \pm 0.4 \%$ (CS), in erythrocytes $-76.4 \pm 1.3 \%$ and $73.8 \pm 0.7 \%$, respectively (the differences between the "FW" and "CS" groups are statistically insignificant) (Fig.4).

\section{Discussion}

Comparison of water-salt homeostasis parameters in the body of goldfish in CS conditions and in humans at hypernatremia

The critical salinity studied in the present paper is within the habitable salinity range of water for the freshwater teleosts. The living of goldfish in saline estuarine sections of rivers and the absence of mortality in experiments on fish acclimation to CS evidence the effectiveness of the homeostatic mechanisms of fish in CS conditions $(21,25,26)$. This was also confirmed by the results of the present study. Water salinity is a factor in the regulation of the metabolism in aquatic poikilotherms. Its rise induces a stress response in the body of stenohaline freshwater teleosts, manifested in an increase in the titer of circulating cortisol, which adapts the energy metabolism of fish to high salinity $(27,28)$. Goldfish tolerates water salinity to $6.0 \mathrm{~g} / \mathrm{L}$ without pronounced signs of stress (29). At water salinity in the range of $8.0-10.0 \mathrm{~g} / \mathrm{L}$ and up to the upper limit of tolerable salinity (CS), the concentration of $\mathrm{Na}^{+}$in the plasma of goldfish and other freshwater Teleostei rises from $\sim 150$ to $200 \mathrm{mmol} / \mathrm{kg}$, the level of cortisol in the blood is elevated, signs of muscle dehydration appear, along with a decreased locomotor activity and growth rates, decreased urine volume, and increased water consumption $(18,19,20,21,27,28,29,30,31,32,33)$.

The results of the present study are consistent with these data. At the $\mathrm{Na}^{+}$level in plasma close to $200 \mathrm{mmol} / \mathrm{kg}$, in the muscles and erythrocytes of goldfish, a tendency towards a decrease in the total water content was noted (the differences are statistically insignificant), which indicates the development of initial signs of tissue (cellular) dehydration. The hyperionic status of the goldfish plasma relative to CS was maintained at an insignificant level $\left(\left(\Delta \mathrm{Na}^{+}\right) \approx 1 \mathrm{mmol} / \mathrm{kg}\right)$ compared to that in the fish of control group $\left(\left(\Delta \mathrm{Na}^{+}\right) \approx 144 \mathrm{mmol} / \mathrm{kg}\right)$. Nevertheless, this value $(\sim 1 \mathrm{mmol} / \mathrm{kg})$ supported the minimal inflow of water into the body, termination of which would lead to death. In such conditions, we did not find a decrease in the plasma protein concentration and total water content in the goldfish blood. This indirectly indicates the stability of its protein and water homeostasis.

In humans, the state of hypernatremia is considered to be at the plasma $\mathrm{Na}^{+}$concentration of more than $145 \mathrm{mmol} / \mathrm{kg}$. This may occur in infants and the elderly people with an inadequate water replenishment as well as in the patients with neurological impairment of the thirst control mechanism $(34,35)$. Hyperna- tremia may develop with the use of saline $0.9 \%$ solution (154 $\left.\mathrm{mEq} / \mathrm{L} \mathrm{Na}^{+}\right)(13)$ and in rare cases of forced long-term use of seawater. Unlike freshwater Teleostei, which adapt to elevated plasma $\mathrm{Na}^{+}$levels to $200 \mathrm{mmol} / \mathrm{kg}$ (20), even minimal changes in this parameter in humans lead to dangerous consequences at the cellular level $(11,36)$. The concentration body $\mathrm{Na}^{+}$is under the control of many hormones: vasopressin, cortisol, aldosterone, renin, angiotensin II, urotensin II, natriuretic peptides, dopamine, insulin, apelin, etc. and its deviations from the norm are regarded as manifestations of endocrine pathology (37). Rapid correction of hypernatremia may lead to cerebral oedema (35). With prolonged dysnatremia, adaptation processes take place in the cells to balance the osmolality of the intracellular fluid with the extracellular fluid. However, the accompanying metabolic changes are dangerous due to the risk of developing hyperosmotic encephalopathy, osmotic demyelization and rhabdomyolysis, at which the death rate reaches $50 \%(38)$.

The coordination of changes in the water salinity and the organization of HDL in goldfish

The present study revealed that changes in water salinity caused changes in the water-salt balance in goldfish. These changes are manifested in alterations in the concentration of $\mathrm{Na}^{+}$in cells/ tissues/body fluids and in the form of minor changes in the content of total water in muscles and erythrocytes.

In the fish plasma, the sodium concentration varied in the following sequence: $144.8 \pm 4.3 \mathrm{mmol} / \mathrm{kg}(\mathrm{FW}) \rightarrow 197.6 \pm 6.7 \mathrm{mmol} /$ $\mathrm{kg}(\mathrm{CS}) \rightarrow 132.6 \pm 8.3 \mathrm{mmol} / \mathrm{kg}(\mathrm{FW})$. Against the background of these changes, remodelling of blood plasma HDL took place in the following order: $125 / 110 \mathrm{kDa} H D L$ ("FW") $\rightarrow$ 85/60 kDa HDL ("CS") $\rightarrow 125 / 110 \mathrm{kDa} H D L$ ("FW rev "). The corresponding dynamics of the number of Apo molecules in single HDL particle may be represented as 6-8(FW) $\rightarrow 4-5(\mathrm{CS}) \rightarrow 6-8(\mathrm{FW})$. These facts indicate the reversible nature of HDL remodelling. The calculated values of the number of Apo molecules in the composition of single HDL particle in goldfish plasma do not contradict the human HDL models $(39,40,41)$. Finding of HDL remodelling in goldfish at similar changes in plasma sodium levels in humans suggests the possibility of breakdown and restoration of lipoprotein particles in human blood during hypernatremia.

\section{Conclusions}

The osmotic activity of HDL and their high titer in the plasma of freshwater Teleostei suggest a significant contribution of this group of lipoproteins to the creation of colloidal osmotic pressure in fish plasma (42). The breakdown of HDL into small forms leads to an increase in the total amount of osmotically active particles in plasma, while the restoration of large HDL from small forms leads to a decrease in this amount. Such dynamics becomes important in CS conditions, when the organism of goldfish is in a hypertonic environment and already has the initial signs of tissue dehydration. Considering the practically unchanged level of total protein and the relative content of HDL in fish plasma during the experiment, as well as the dynamics of changes in the number 
of Apo molecules in a single particle, it may be assumed with a high degree of probability that HDL decay was accompanied by an increase in the number of particles per unit volume of plasma by factor of almost 1.5. An increase in the number of osmotically active particles in the plasma of fish from the "CS" group contributes to the retention of water in the body and the maintenance of osmotic homeostasis in the critical salinity zone, in which, due to plasma hypernatremia, the inflow of water into the body is extremely limited. The breakdown of HDL, contributing to an increase in plasma osmolality, may facilitate additional "pumping" of water into the body.

The analysis of published data revealed that there is no information on the breakdown of HDL particles in human plasma at hypernatremia. Nevertheless, the possibility of their decay is indirectly indicated by data on the decay of other human plasma proteins under the influence of an increased level of $\mathrm{Na}^{+}$. Thus, in vitro, at the concentration of $\mathrm{Na}^{+}$in the solution of only 150 $\mathrm{mmol} / \mathrm{kg}$, the decomposition of the tetrameric human plasma of alpha-2-macroglobulin into dimers (in $\sim 5 \%$ of the tetramer pool) was registered and the breakdown was accompanied by a change in the functional profile of the protein (43). In this example, the concentration of $\mathrm{Na}^{+}$in the solution $(150 \mathrm{mmol} / \mathrm{kg})$ does not exceed its titer in the physiological solution used in clinical practice (154 mEq/L) (13).

Consequently, there is a risk of disintegration of protein complexes and lipoprotein structures of the plasma in the patients infused with such a solution. The importance of studying the HDL response to hypernatremia is determined by the fact that these particles are not only lipid carriers, but also a part of the body's complex defence $(14,17)$. The presence in their composition of dozens of "minor" proteins involved in various biochemical processes (44), in the event of HDL degradation, may lead to undesirable functional consequences. The results of the HDL response to hypernatremia revealed in fish may be useful in the development of protocols for the use of infusion solutions in clinical practice, as well as at using synthetic HDL particles (rHDL) (45).

Considering that, the pathogenetic mechanisms responsible for the development of hypernatremia and its effects in humans are not yet fully clear and that hypernatremia is considered a potentially life-threatening condition (38), it seems promising to use fish as model objects for studying its effects.

\section{References}

1. Anderson RJ et al. Hyponatremia: a prospective analysis of its epidemiology and the pathogenetic role of vasopressin. Ann Intern Med 1985; 102 (2): 164-168.

2. Ayus JC, Arieff AI. Chronic hyponatremic encephalopathy in postmenopausal women: association of therapies with morbidity and mortality. JAMA 1999; 281 (24): 2299-2304.

3. Liamis GL et al. Mechanisms of hyponatraemia in alcohol patients. Alcohol Alcohol 2000; 35 (6): 612-616.

4. Mendes RS et al. Predialysis hypernatremia is a prognostic marker in acute kidney injury in need of renal replacement therapy. J Crit Care 2015; 30 (5): 982-987.
5. Han SS et al. Dysnatremia, its correction, and mortality in patients undergoing continuous renal replacement therapy: a prospective observational study. BMC Nephrol 2016; 17: 2.

6. Kurtz I, Nguyen MK. Evolving concepts in the quantitative analysis of the determinants of the plasma water sodium concentration and the pathophysiology and treatment of the dysnatremias. Kidney Int 2005; 68 (5): 1982-1993.

7. Wald $\mathbf{R}$ et al. Changing incidence and outcomes following dialysisrequiring acute kidney injury among critically ill adults: a population-based cohort study. Am J Kidney Dis 2015; 65 (6): 870-877.

8. Berry PL, Belsha CW. Hyponatremia. Pediatr Clin North Am 1990. 37 (2): 351-363.

9. Conley SB. Hypernatremia. Pediatr Clin North Am 1990; 37 (2): 365-372.

10. Park YJ et al. Successful treatment in the patient with serum sodium level greater than 200 mEq/L. J Korean Med Sci 2000; 15 (6): 701-703.

11. Nguyen MK, Kurtz I. New insights into the pathophysiology of the dysnatremias: a quantitative analysis. Am J Physiol Renal Physiol 2004; 287 (2): F172-180.

12. Nguyen MK et al. Defining the role of albumin infusion in cirrhosisassociated hyponatremia. Am J Physiol Gastrointest Liver Physiol 2014; 307 (2): G229-232.

13. Besen BA et al. Fluid and electrolyte overload in critically ill patients: An overview. World J Crit Care Med 2015; 4 (2): 116-129.

14. Kudinov VA et al. High-Density Lipoproteins as Homeostatic Nanoparticles of Blood Plasma. Int J Mol Sci 2020; 21 (22).

15. Babin PJ, Vernier JM. Plasma lipoproteins in fish. J Lipid Res 1989; 30 (4): 467-489.

16. Phillips MC. New insights into the determination of HDL structure by apolipoproteins: Thematic review series: high density lipoprotein structure, function, and metabolism. J Lipid Res 2013; 54 (8): 2034-2048.

17. Vaisar T. Proteomics investigations of HDL: challenges and promise. Curr Vasc Pharmacol 2012; 10 (4): 410-421.

18. Martemyanov VI, Poddubnaya NY. Volume regulation of muscle cells in the carp Cyprinus carpio in response to hypernatremia. Bratisl Med J 2019; 120 (1): 52-57.

19. Martemyanov VI, Poddubnaya NY. Regulation ranges and patterns of adaptation to hyponatremia by cells of various organs and tissues of vertebrate animals. Bratisl Med J 2020; 121 (3): 218-224.

20. Lahlou B, Henderson IW, Sawyer WH. Sodium exchanges in goldfish (Carassius auratus L.) adapted to a hypertonic saline solution. Comp Biochem Physiol 1969; 28 (3): 1427-1433.

21. Martemyanov VI, Vasiliev AS. Regulation of Volumes of the Muscle, Liver, and Brain Erythrocytes in Crucian Carp Carassius auratus (Cyprinidae) in Response to Increase in the Osmotic Concentration in Blood Plasma. Journal of Ichthyology 2018; 58: 563-569.

22. Martemyanov V. Methods to determine total water, free water fraction, and attached water fraction in the organism and tissues of hydrobionts. Water: chemistry and ecology 2014; 2: 86-95.

23. Itzhaki RF, Gill DM. A micro-biuret method for estimating proteins. Analytical Biochemistry 1964; 9 (4): 401-410.

24. Laemmli UK. Cleavage of Structural Proteins during the Assembly of the Head of Bacteriophage T4. Nature 1970; 227: 680. 
25. Andreeva AM. The role of structural organization of blood plasma proteins in the stabilization of water metabolism in bony fish (Teleostei). Journal of Ichthyology 2010; 50 (7): 552-558.

26. Martemyanov VI, Borisovskaya EV. Indices of salt and water metabolism in tubenose goby Proterorhinus marmoratus pallas, introduced into Rybinsk Reservoir, and in indigenous carp Cyprinus carpio L. Depending on environmental salinity. Russian Journal of Biological Invasions 2012; 3 (2): 110-117.

27. Mommsen T, Vijayan M, Moon T. Cortisol in teleost Dynamics, mechanisms of action, and metabolic regulation. Reviews in Fish Biology and Fisheries 1999; 9: 211-268.

28. Nakkrasae LI, Wisetdee K, Charoenphandhu N. Osmoregulatory adaptations of freshwater air-breathing snakehead fish (Channa striata) after exposure to brackish water. J Comp Physiol B 2015; 185 (5): 527-537.

29. Luz RK et al. Growth, food intake regulation and metabolic adaptations in goldfish (Carassius auratus) exposed to different salinities. Aquaculture 2008; 276 (1): 171-178.

30. Abo Hegab S, Hanke W. The significance of cortisol for osmoregulation in carp (Cyprinus carpio) and tilapia (Sarotherodon mossambicus). Gen Comp Endocrinol 1984; 54 (3): 409-417.

31. Wendelaar Bonga SE, The stress response in fish. Physiol Rev 1997; 77 (3): 591-625.

32. Burgdorf-Moisuk A, Mitchell MA, Watson M. Clinical and physiologic effects of sodium chloride baths in goldfish (Carassius auratus). $\mathrm{J}$ Zoo Wildl Med 2011; 42 (4): 586-592.

33. Küçük S. The effects of salinity on growth of goldfish, Carassius auratus and crucian carp, Carassius carassius. 2013.

34. Braun MM, Barstow CH, Pyzocha NJ. Diagnosis and management of sodium disorders: hyponatremia and hypernatremia. Am Fam Physician 2015; 91 (5): 299-307.
35. Sonani B, Naganathan S, Al-Dhahir MA. Hypernatremia, in StatPearls. 2021, 2021, StatPearls Publishing LLC.: Treasure Island FL.

36. Muhsin SA, Mount DB. Diagnosis and treatment of hypernatremia. Best Pract Res Clin Endocrinol Metab 2016; 30 (2): 189-203.

37. Liamis G, Milionis HJ, Elisaf M. Endocrine disorders: causes of hyponatremia not to neglect. Ann Med 2011; 43 (3): 179-187.

38. Naik KR, Saroja AO. Seasonal postpartum hypernatremic encephalopathy with osmotic extrapontine myelinolysis and rhabdomyolysis. J Neurol Sci 2010; 291 (1-2): 5-11.

39. Gauthamadasa $\mathbf{K}$ et al. Speciated Human High-Density Lipoprotein Protein Proximity Profiles. Biochemistry 2010; 49: p. 10656-10665.

40. Huang $\mathbf{R}$ et al. Apolipoprotein A-I structural organization in highdensity lipoproteins isolated from human plasma. Nat Struct Mol Biol 2011; 18 (4): 416-422.

41. Wu $\mathbf{Z}$ et al. The low resolution structure of ApoA1 in spherical high density lipoprotein revealed by small angle neutron scattering. J Biol Chem 2011; 286 (14): 12495-12508.

42. Andreeva A. The Strategies of Organization of the Fish Plasma Proteome: with and without Albumin. Russian Journal of Marine Biology 2019; 45: 263-274.

43. Wyat AR et al. Alpha-2-Macroglobulin Is Acutely Sensitive to Freezing and Lyophilization: Implications for Structural and Functional Studies. PLoS One 2015; 10 (6): e0130036.

44. Kontush A et al. Structure of HDL: particle subclasses and molecular components. Handb Exp Pharmacol 2015; 224: 3-51.

45. Dullens SP, Plat J, Mensink RP. Increasing apoA-I production as a target for CHD risk reduction. Nutr Metab Cardiovasc Dis 2007; 17 (8): 616-628.

Received September 28, 2021. Accepted November 23, 2021. 